\title{
Long-term cure of high-grade spinal cord glioma in a pediatric patient who underwent cordectomy
}

\author{
${ }^{*}$ R. Webster Crowley, MD, ${ }^{1}$ Rebecca M. Burke, MD, PhD, ${ }^{1}$ M. Beatriz S. Lopes, MD, PhD, ${ }^{2}$ \\ D. Kojo Hamilton, MD, ${ }^{3}$ and John A. Jane Sr., MD, PhD ${ }^{1}$ \\ Departments of ${ }^{1}$ Neurological Surgery and ${ }^{2}$ Pathology, University of Virginia Health System, Charlottesville, Virginia; and \\ ${ }^{3}$ Department of Neurosurgery, University of Pittsburgh, Pennsylvania
}

\begin{abstract}
High-grade spinal cord gliomas are rare and carry a poor prognosis. A number of treatment modalities exist for spinal cord gliomas, but no consensus exists regarding their management. Cordectomy represents a possible option for treating these lesions; however, few cases have been reported in adults, and none have been reported in the pediatric population. The authors describe the use of cordectomy for the treatment of a high-grade spinal glioma in a 9-year-old boy who remains cancer free 14 years following his initial presentation.
\end{abstract}

http://thejns.org/doi/abs/10.3171/2015.7.SPINE15656

KEY WORDS cordectomy; spinal glioma; high-grade; tanycytic ependymoma; oncology

I NTRAMEDULLARY spinal cord gliomas are relatively rare lesions, accounting for approximately $20 \%-25 \%$ of all primary spinal cord tumors. ${ }^{2,4}$ Of this small population of patients with intramedullary gliomas, only $7.5 \%-17 \%$ have high-grade lesions, a percentage that varies according to the type of glioma and the age of the patient. ${ }^{2,4,18}$ Unfortunately, much like high-grade gliomas of the brain, high-grade gliomas of the spinal cord are associated with a dismal prognosis, one that may also be worse for lesions in the thoracic spine. ${ }^{2,6,18}$ Moreover, there is no consensus regarding their treatment.

In general, treatment often consists of surgical debulking followed by radiation therapy and, occasionally, chemotherapy. Cordectomy is used infrequently, for, despite its potential utility, there are substantial associated risks with unproven benefits, since high-grade lesions are believed to be incurable. Thus, there has been only a handful of reported cases in which cordectomy has been employed for spinal neoplasms. ${ }^{1,7,9,14,15,21,25}$ Here, we present the case of a 9-year-old boy who underwent cordectomy for the treatment of a high-grade spinal glioma. The patient has been disease free in the 14 years since his diagnosis and in the 13 years since undergoing cordectomy.

\section{Case Report}

Presentation

This 9-year-old boy originally presented to medical attention in 2001 with a several-month history of a widebased swinging gait and difficulty running. MRI of the spinal cord revealed an enhancing intramedullary T9-12 mass that appeared consistent with a diffusely infiltrative astrocytoma (Fig. 1).

\section{Initial Operation and Histopathological Findings}

After discussing the options with his family, the patient underwent T9-12 laminectomies and debulking of the tumor. Due to the infiltrative nature of the lesion, a gross-total resection was not attempted in an effort to spare normal spinal cord function. Electrophysiological neuromonitoring was performed using somatosensory and motor evoked potentials, and alteration of the former was observed at the time of the midline myelotomy. Pathology demonstrated a glioma composed of glial fibrillary acidic protein (GFAP)-immunoreactive cells with elongated processes and homogeneous oval nuclei. The tumor cells were arranged in a palisading-like fashion resembling a "polar

ABBREVIATIONS GBM = glioblastoma multiforme; GFAP = glial fibrillary acidic protein.

SUBMITTED June 4, 2015. ACCEPTED July 15, 2015.

INCLUDE WHEN CITING Published online August 7, 2015; DOI: 10.3171/2015.7.SPINE15656.

* Drs. Crowley and Burke contributed equally to this work. 


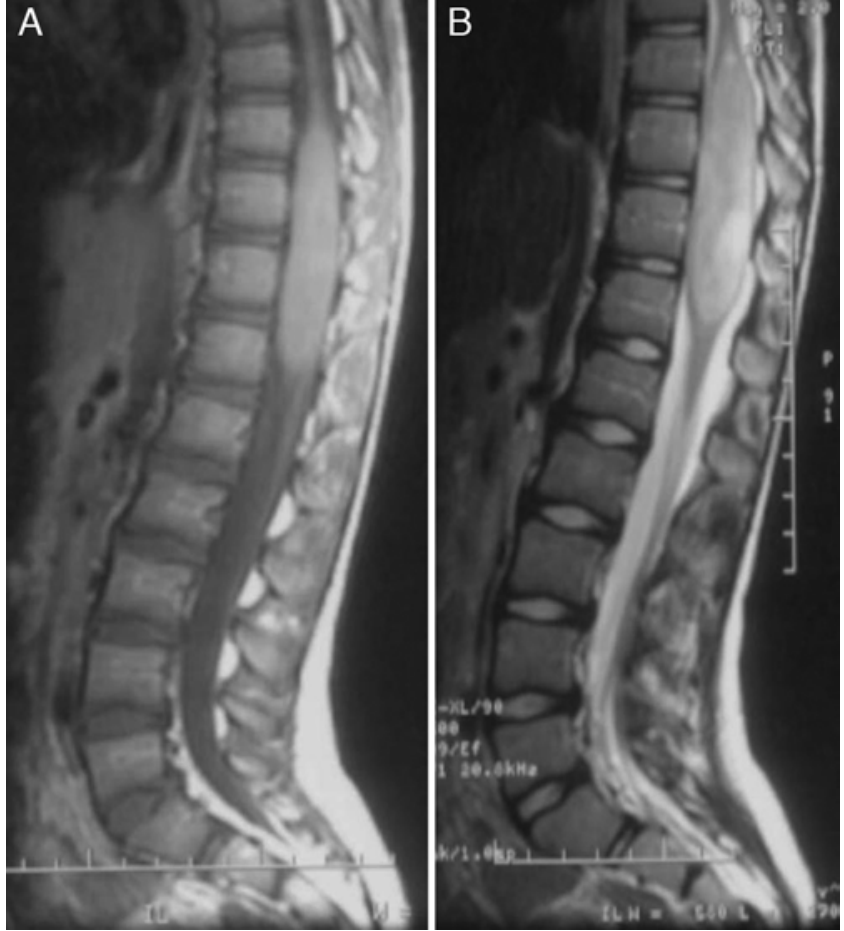

FIG. 1. Sagittal contrast-enhanced T1-weighted MR image (A) and sagittal T2-weighted MR image (B) demonstrating an enhancing mass extending from T-9 to T-12.

spongioblastoma-like" arrangement. No Rosenthal fibers or hyaline droplets were observed. The tumor exhibited minimal cellular atypia and no necrosis or microvascular proliferation. Mitotic figures were rare, but the Ki 67 labeling index was mildly elevated. Though the tumor did not fit the typical appearance of a pilocytic astrocytoma, a diagnosis of low-grade astrocytoma was made (Fig. 2).

\section{Postoperative Course}

The patient was able to ambulate short distances with the aid of orthotics and crutches. One month later, MRI revealed a mildly enhancing residual mass that extended from T-9 to the conus medullaris (Fig. 3). Subsequently, the patient received a 1-month course of external-beam radiotherapy, with an overall dose of $3960 \mathrm{cGy}$ in 22 treatment fractions utilizing a 3 -field spinal technique.

Following radiotherapy, the patient returned to normal activity and regained the ability to participate in athletic activities. However, several months later he experienced acute-onset paraparesis, paresthesias, back pain, and spasms. MRI revealed progression of the lesion such that it was slightly increased in size from the original tumor. In addition, associated edema was noted to extend from the tumor caudally to the conus and rostrally to the level of C-5, leading to weakness in the upper extremities.

\section{Second Operation and Histopathological Findings}

After further discussion with the family, the patient underwent reoperation with internal debulking of the tumor while intraoperative electrophysiological neuromonitoring was performed. Pathology confirmed a fibrillary glioma

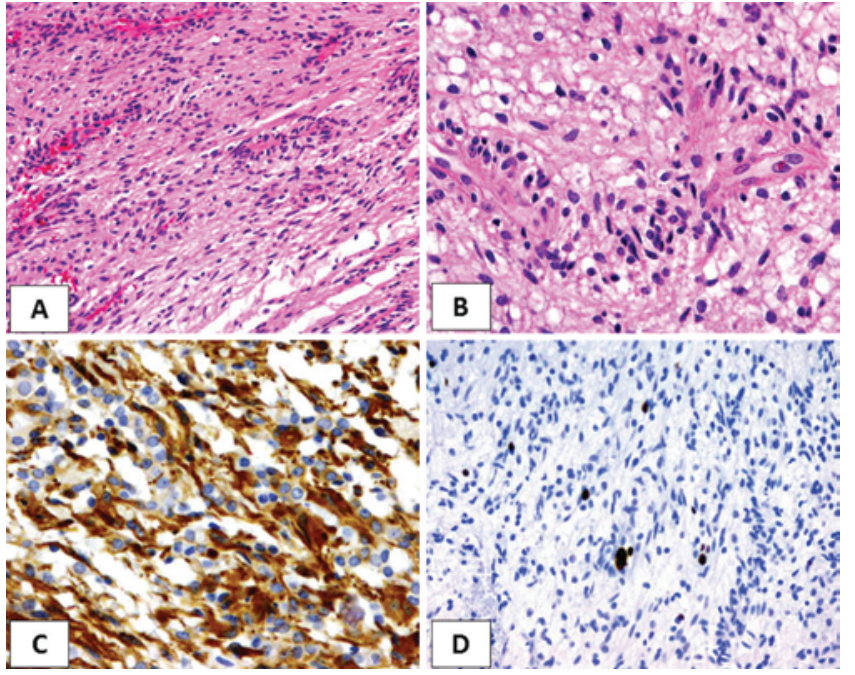

FIG. 2. First surgical biopsy specimen. A and B: The tumor was composed of slightly elongated, fibrillary cells arranged in delicate fascicles. C: The tumor cells were strongly immunopositive for GFAP. D: Mitotic figures were rare and the Ki 67 proliferative index was low. H \& E, original magnification $\times 100$ (A) and $\times 200$ (B); GFAP immunohistochemistry $(\mathrm{IHC})$, original magnification $\times 100(\mathrm{C})$; and Ki $67 \mathrm{IHC}$, original magnification $\times 100$ (D). Figure is available in color online only.

with histopathological features similar to those seen in the previous biopsy sample. However, in this larger specimen, the tumor exhibited infiltration of the spinal cord parenchyma without a definitive tumor-spine parenchyma in-

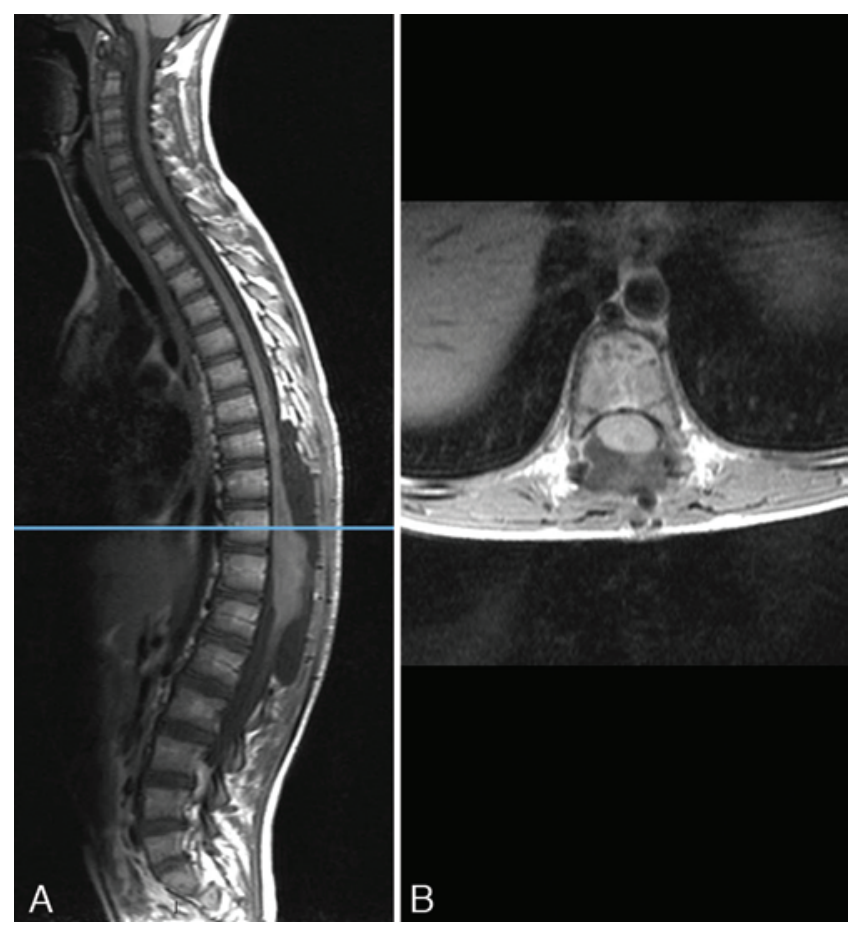

FIG. 3. Postoperative images demonstrating a mildly enhancing residual mass extending from T-9 to the conus medullaris. A: Sagittal contrastenhanced T1-weighted MR image. The blue line denotes the T-10 level. B: Corresponding axial image at T-10. Figure is available in color online only. 


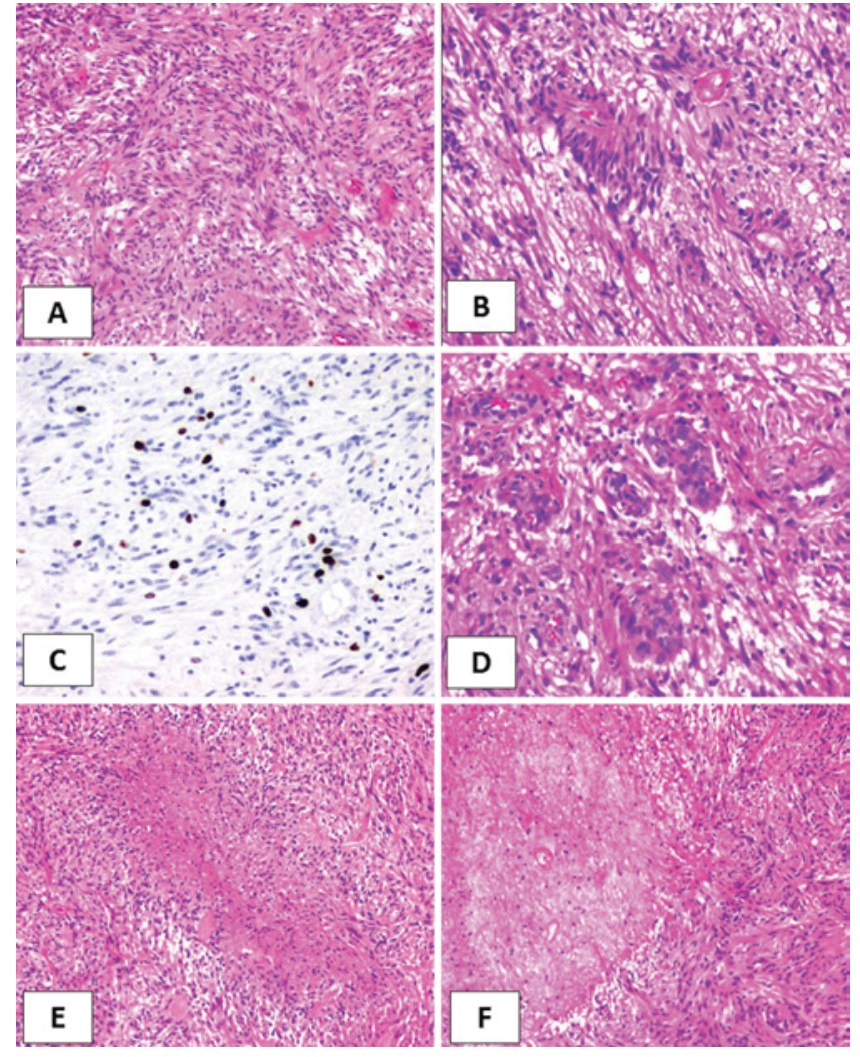

FIG. 4. Second surgical specimen. Fibrillary cells arranged on fascicular arrangements similar to previous biopsy (A). The tumor cells diffusely infiltrated the spinal parenchyma most conspicuously by the perivascular spaces (B). Features of anaplastic transformation including increased mitotic activity and Ki 67 index (C), microvascular proliferation (D), and palisading necrosis $(\mathrm{E})$ were present in this second biopsy. Several areas of radiation necrosis were also present $(F)$. $H$ \& E, original magnification $\times 100(\mathrm{~A}, \mathrm{E}$, and $\mathrm{F})$ and $\times 200(\mathrm{~B}$ and $\mathrm{D})$; and $\mathrm{Ki} 67 \mathrm{IHC}$, original magnification $\times 100(C)$. Figure is available in color online only.

terface (Fig. 4). Although the glioma infiltrated the parenchyma within the perivascular spaces, perivascular pseudorosettes were not observed. Unlike the previous biopsy sample, in this surgical specimen the tumor showed, in addition to areas of radiation necrosis, multifocal areas of palisading necrosis and microvascular proliferation. Mitotic activity and the Ki 67 labeling index were elevated. Similar to the previous biopsy sample, obvious features of a pilocytic astrocytoma including Rosenthal fibers and hyaline droplets were not observed. Because of the increased anaplastic features, we established a diagnosis of a high-grade astrocytoma, at least WHO Grade III. Postoperatively, the patient had substantially decreased strength bilaterally, with Grade 0/5 strength in both legs, and loss of proprioception and light touch below the T-8 level.

\section{Second Postoperative Course}

Two weeks after his second surgery, follow-up MRI revealed residual enhancement from T-9 to T-12, with significantly improved edema and no abnormal enhancement rostral to the tumor. Abnormal enhancement was also absent throughout the remainder of the craniospinal axis (Fig. 5). In light of the increasingly aggressive nature

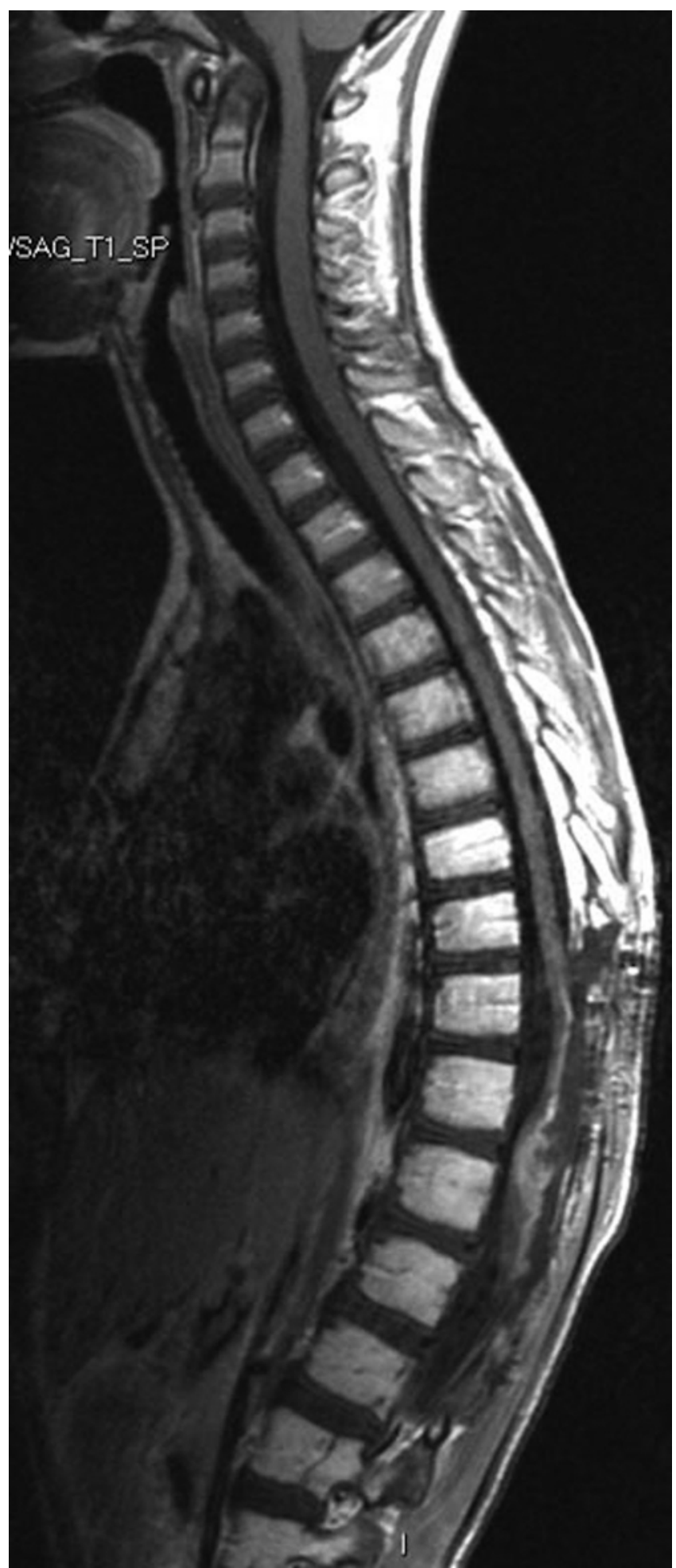

FIG. 5. Sagittal contrast-enhanced T1-weighted MR image demonstrating postoperative changes following the second surgical debulking. Residual enhancement is seen from T-9 to T-12 with no abnormal enhancement throughout the remainder of the craniospinal axis.

of the tumor, as well as the absence of return of function inferior to the tumor, a cordectomy was recommended. The patient and his family were counseled regarding the expected permanent neurological deficits, and the absence 


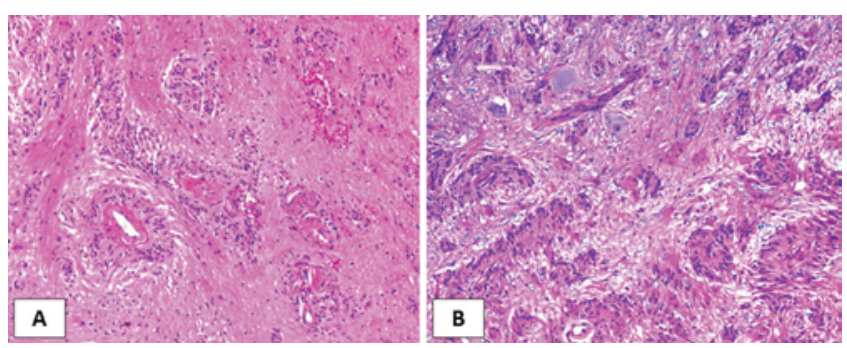

FIG. 6. Third surgical specimen following cordectomy. A: The tumor exhibited similar features as the second surgical specimen. Prominent diffuse infiltration by tumor of the perivascular spaces and diffuse infiltration of the gray and white matter of the cord can be seen. B: Note posterior column neurons and myelinated fibers intermixed with tumor cell fascicles. H \& E, original magnification $\times 100(A)$; and Luxol Fast Blue, original magnification $\times 100(B)$. Figure is available in color online only.

of a proven benefit to the surgery, before they decided to proceed with a cordectomy for potentially definitive treatment of his high-grade lesion.

\section{Third Operation}

The patient was brought back to the operating room where he underwent T6-L1 laminectomies. In an attempt to achieve a wide margin of resection, an intraoperative biopsy was performed at the T-6 level, 3 levels above the radiographic extent of the lesion. Although a more rostral resection would have widened the surgical margin to known tumor, it was felt that stopping at T-6 would minimize the potential risk of resultant autonomic dysreflexia. Once the intraoperative biopsy demonstrated normal spinal cord with no evidence of tumor, the T-6 vertebra was selected as the rostral margin of the resection and a complete removal of the spinal cord from T-6 to the conus was performed, with transection of the accompanying exiting nerve roots. Pathology again was consistent with a highgrade astrocytoma (Fig. 6).

\section{Third Postoperative Course}

By postoperative Day 2, the patient was out of bed without difficulty and did not have any unexpected deficits. Postoperative MRI revealed complete removal of all abnormal spinal cord, and the patient was discharged to a rehabilitation facility on postoperative Day 3. No further adjuvant therapy was initiated.

Beginning 2 months after the cordectomy, the patient underwent serial MRI every 6 months for 3 years, followed by annual examinations, all of which showed no recurrence of his tumor. Approximately 2 years after surgery, the patient presented with paralytic kyphoscoliosis, which was treated with posterior instrumentation and T5-L4 fusion to correct his substantial deformity. This required reoperation 2 years later for extension of the fusion. MRI and radiography performed 8 years following his initial surgery demonstrated expected postoperative changes and failed to show evidence of a syrinx or enhancing lesions (Fig. 7).

Ultimately, the patient was able to resume athletic activity. He eventually received an athletic scholarship to the University of Illinois for wheelchair basketball and later was a member of the Under-23 US Men's National Wheel- chair Basketball Team (Fig. 8). He has been disease free for the last 13 years.

\section{Reclassification of the Tumor}

During the recent review of the pathological materials for preparation of this manuscript, a question of the precise diagnosis of the tumor was raised. The intense fibrillary nature and fascicular arrangements of this glioma, in conjunction with the lack of features suggesting a pilocytic astrocytoma, raised the possibility that the tumor might have been a tanycytic ependymoma, a rare variant of ependymoma that may exhibit histopathology features indistinguishable from pilocytic astrocytomas. ${ }^{8,12}$ This diagnosis was not entertained at the time of the initial resections (20012002). Additional immunohistochemical stains performed at this time demonstrated the tumor cells' lack of reactivity for the transcription factor Olig-2, a feature described in spinal cord ependymomas, ${ }^{19}$ and the presence of dot-like epithelial membrane antigen positivity in the tumor cells. Therefore, despite the infiltrative nature of this glioma, we now believe that the tumor would be classified as an anaplastic tanycytic ependymoma, WHO Grade III.

\section{Discussion}

We have presented the successful treatment option for a high-grade spinal cord glioma, describing a complete removal of the spinal cord, and its associated nerve roots, beginning approximately 2 levels above the level of the tumor. We feel that there are several aspects of this particular case that warrant further discussion; however, what is perhaps most remarkable is the infrequency with which this procedure is used.

While cordectomy has been advocated for a number of neurosurgical conditions, including intractable pain, spasticity, and syringomyelia, $, 510,13,23,24$ there is little mention of its being performed in the setting of spinal cord tumors. In fact, to our knowledge, the literature contains only 7 reported cases in which cordectomy was used to treat spinal cord tumors, ${ }^{1,7,9,14,15,21,25}$ none of which involved pediatric patients.

The first mention of using cordectomy to treat a spinal cord tumor was in 1949, when MacCarty and Kiefer ${ }^{14}$ described performing it to treat a thoracic glioblastoma multiforme (GBM) in a 25-year-old man. Approximately 40 years later, a cordectomy for a spinal cord tumor was again described by Tokoro et al., ${ }^{25}$ who performed the procedure for a recurrent neurinoma of the thoracic spine. While the lesion was not malignant, it had caused syringobulbia-myelia with resultant central sleep apnea, both of which resolved after surgery.

Later, in 2002, Kyoshima et al. ${ }^{9}$ described their use of cordectomy for an anaplastic astrocytoma of the thoracolumbar spinal cord in a 48 -year-old man. Similar to our patient, theirs had undergone multiple subtotal resections of a low-grade astrocytoma, and the patient eventually developed paraplegia. However, the cordectomy was not performed until roughly 2 years after the tumor had progressed to a malignant glioma, and the patient died of tumor recurrence and dissemination 15 months after the cordectomy. 

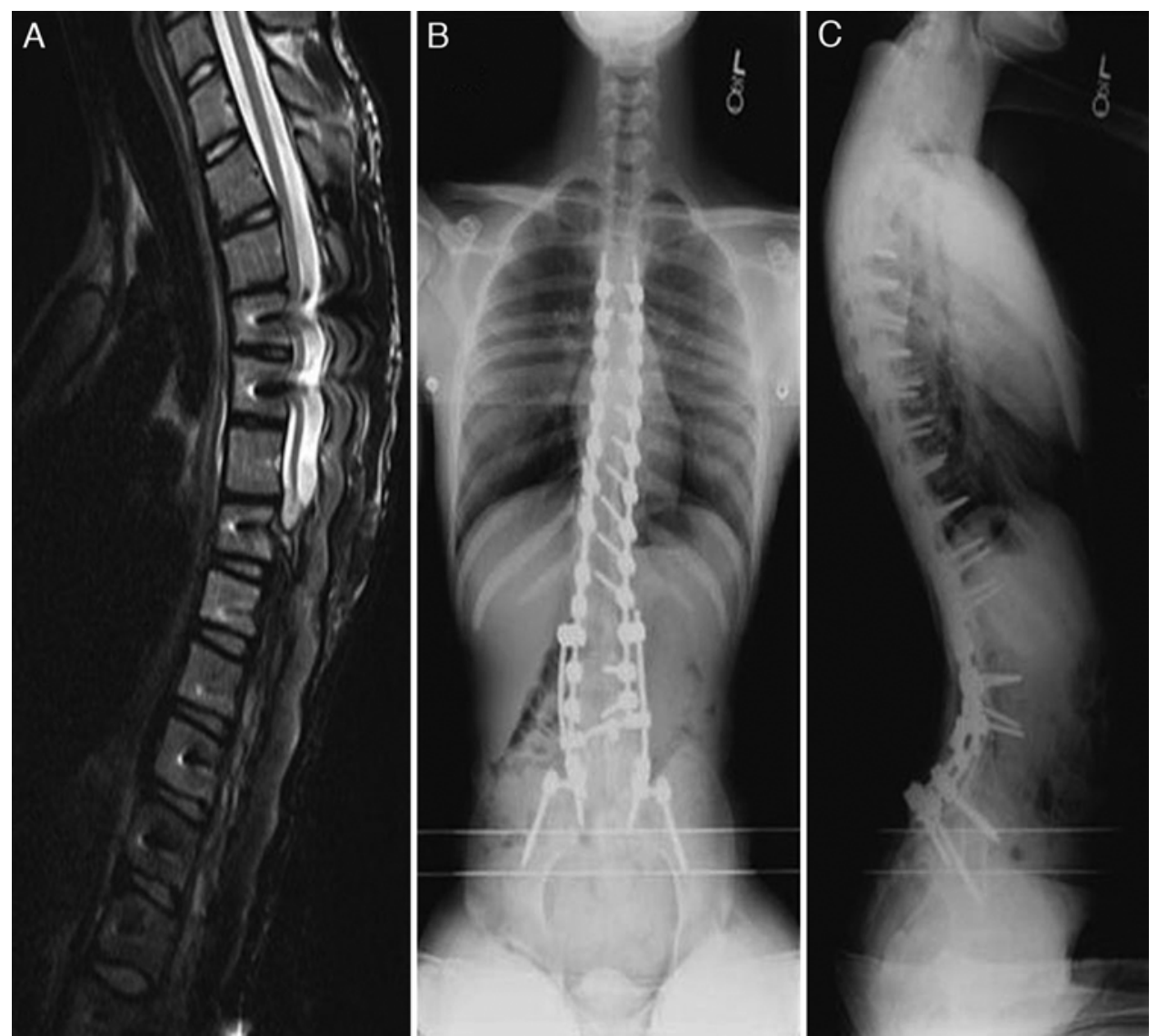

FIG. 7. Sagittal T2-weighted MR image (A) and radiographs (B [anteroposterior] and $\mathbf{C}$ [lateral]) demonstrating expected postoperative changes and continued absence of disease. The MR image demonstrates transection of the spinal cord at T-6 with no evidence of tumor recurrence. The radiographs show the final spinal fusion construct.

In 2005, Raza et al. ${ }^{21}$ reported performing cordectomy in a 65-year-old patient with a recurrent atypical meningioma of the thoracic spine, although they were unable to achieve a total resection due to persistent meningeal involvement. Marchan et al. ${ }^{15}$ performed cordectomy for a spinal GBM in a 50-year-old man. Approximately 3 months after establishing the diagnosis of spinal GBM and after the patient had become progressively paraplegic despite radiotherapy and chemotherapy, Marchan and colleagues opted to undertake a spinal cordectomy rather than debulk the lesion. The patient remained disease free for approximately 6 years before developing multiple cerebellar GBMs and dying shortly thereafter.

Most recently, Ewelt and associates reported on a 27-year-old woman with a recurrent T9-12 anaplastic astrocytoma treated by cordectomy. The patient had previously undergone surgical debulking, radiation treatment, and temozolomide-based chemotherapy without successful eradication of the lesion. Subsequently, the patient developed paraplegia as a result of tumor progression. A cordectomy was ultimately performed between the T-8 and T-9 levels and no disease recurrence was seen up to 15 months postoperatively.

Regarding ependymomas, a large epidemiological study found that approximately $36 \%$ of ependymomas are located in the spine, but only $13 \%$ of pediatric ependymo- mas are spinal. ${ }^{16}$ In addition, $8.6 \%$ of ependymomas were found to be Grade III. Oh et al. recently reviewed the literature on pediatric spinal cord ependymomas and, after excluding myxopapillary ependymomas, found a total of 58 cases for their analysis. ${ }^{18}$ They indicated that $17 \%$ of the individuals in this group had Grade III lesions.

As previously stated, the prognosis for high-grade spinal gliomas is poor, and certainly the treatment options available for many of these infiltrative lesions are not ideal. While some advocate function-preserving subtotal resection followed by postoperative radiation therapy, or even radiation therapy alone, ${ }^{17,22}$ others feel that radiation therapy may be of limited value in children and therefore recommend radical resection despite the increased risk of neurological deficit. ${ }^{2,20}$ However, largely due to the relative infrequency of these lesions, no consensus exists regarding their management. Although our patient was initially diagnosed with a low-grade glioma, the infiltrative nature of the tumor and the elevated Ki 67 labeling index portended a more aggressive course. Therefore, after discussing further aggressive surgery, observation, or radiotherapy, the decision was made to proceed with adjuvant radiation following the patient's first surgery. Once the tumor worsened, radical surgery became a more reasonable option. While there have been few reports of cordectomy for highgrade gliomas of the spinal cord, we felt that our patient's 


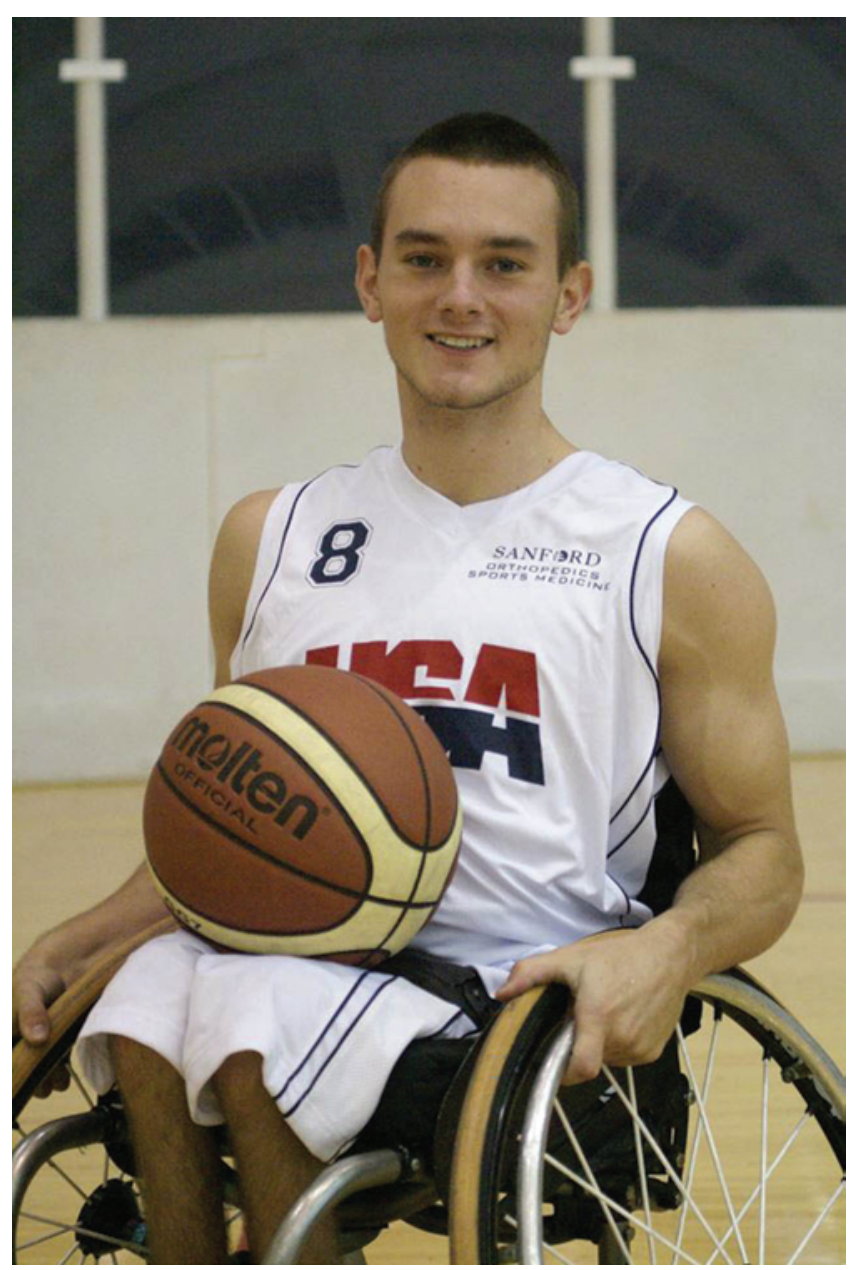

FIG. 8. The patient as a member of the Under-23 US Men's National Wheelchair Basketball Team. The picture was taken approximately 12 years after his cordectomy. Figure is available in color online only.

preexisting paraplegia below the level of the tumor, combined with the worsening tumor grade, ultimately made him a good candidate for complete excision of the spinal cord above the lesion. In hindsight, we do not believe that our recent reclassification of his tumor as a WHO Grade III anaplastic tanycytic ependymoma would have changed our recommendations.

Another aspect of our patient's care that is worth mentioning is the development of kyphoscoliosis, a condition that is frequently seen as a consequence of extensive laminectomies, radiation therapy, or intramedullary tumor resection. ${ }^{3,11,20,22}$ Our patient underwent an 8-level decompression in addition to the spinal cord resection, which eventually required segmental instrumentation and fusion. Because of the increased risk for developing progressive spinal deformity in this patient population, patients should undergo long-term follow-up not just for the management of their tumor, but for observation for the development of deformity.

\section{Conclusions}

We have provided further evidence that cordectomy is a viable option for patients with high-grade spinal cord gliomas, with the potential for cure of the disease. However, evidence demonstrating the success of the procedure is merely anecdotal. Therefore, given the lack of higher levels of evidence demonstrating its efficacy, we believe that complete resection of the spinal cord should likely only be considered for patients with poor neurological function and no evidence of tumor dissemination. It is in this select patient population that cordectomy may have a legitimate role for the management of high-grade spinal cord gliomas.

\section{References}

1. Amini A, Chin SS, Schmidt MH: Malignant transformation of conus medullaris ganglioglioma: case report. J Neurooncol 82:313-315, 2007

2. Cohen AR, Wisoff JH, Allen JC, Epstein F: Malignant astrocytomas of the spinal cord. J Neurosurg 70:50-54, 1989

3. Constantini S, Miller DC, Allen JC, Rorke LB, Freed D, Epstein FJ: Radical excision of intramedullary spinal cord tumors: surgical morbidity and long-term follow-up evaluation in 164 children and young adults. J Neurosurg 93 (2 Suppl):183-193, 2000

4. DeSousa AL, Kalsbeck JE, Mealey J Jr, Campbell RL, Hockey A: Intraspinal tumors in children. A review of 81 cases. $\mathbf{J}$ Neurosurg 51:437-445, 1979

5. Durward QJ, Rice GP, Ball MJ, Gilbert JJ, Kaufmann JC: Selective spinal cordectomy: clinicopathological correlation. J Neurosurg 56:359-367, 1982

6. Epstein FJ, Farmer JP: Pediatric spinal cord tumor surgery. Neurosurg Clin N Am 1:569-590, 1990

7. Ewelt C, Stummer W, Klink B, Felsberg J, Steiger HJ, Sabel $\mathrm{M}$ : Cordectomy as final treatment option for diffuse intramedullary malignant glioma using 5-ALA fluorescenceguided resection. Clin Neurol Neurosurg 112:357-361, 2010

8. Kawano N, Yagishita S, Oka H, Utsuki S, Kobayashi I, Suzuki S, et al: Spinal tanycytic ependymomas. Acta Neuropathol 101:43-48, 2001

9. Kyoshima K, Ito K, Tanabe A, Iwashita T, Goto T, Sato A, et al: Malignant astrocytoma of the conus medullaris treated by spinal cordectomy. J Clin Neurosci 9:211-216, 2002

10. Laxton AW, Perrin RG: Cordectomy for the treatment of posttraumatic syringomyelia. Report of four cases and review of the literature. J Neurosurg Spine 4:174-178, 2006

11. Lee HK, Chang EL, Fuller GN, Aldape KD, Atkinson GJ, Levy LB, et al: The prognostic value of neurologic function in astrocytic spinal cord glioma. Neuro Oncol 5:208-213, 2003

12. Lehman NL: Central nervous system tumors with ependymal features: a broadened spectrum of primarily ependymal differentiation? J Neuropathol Exp Neurol 67:177-188, 2008

13. MacCarty CS: The treatment of spastic paraplegia by selective spinal cordectomy. J Neurosurg 11:539-545, 1954

14. MacCarty CS, Kiefer EJ: Thoracic lumbar and sacral spinal cordectomy; preliminary report. Proc Staff Meet Mayo Clin 24:108-115, 1949

15. Marchan EM, Sekula RF Jr, Jannetta PJ, Quigley MR: Longterm survival enhanced by cordectomy in a patient with a spinal glioblastoma multiforme and paraplegia. Case report. J Neurosurg Spine 7:656-659, 2007

16. McGuire CS, Sainani KL, Fisher PG: Incidence patterns for ependymoma: a surveillance, epidemiology, and end results study. J Neurosurg 110:725-729, 2009

17. O'Sullivan C, Jenkin RD, Doherty MA, Hoffman HJ, Greenberg ML: Spinal cord tumors in children: long-term results of combined surgical and radiation treatment. J Neurosurg 81:507-512, 1994 
18. Oh MC, Sayegh ET, Safaee M, Sun MZ, Kaur G, Kim JM, et al: Prognosis by tumor location for pediatric spinal cord ependymomas. J Neurosurg Pediatr 11:282-288, 2013

19. Otero JJ, Rowitch D, Vandenberg S: OLIG2 is differentially expressed in pediatric astrocytic and in ependymal neoplasms. J Neurooncol 104:423-438, 2011

20. Przybylski GJ, Albright AL, Martinez AJ: Spinal cord astrocytomas: long-term results comparing treatments in children. Childs Nerv Syst 13:375-382, 1997

21. Raza SM, Anderson WS, Eberhart CG, Wolinsky JP, Gokaslan ZL: The application of surgical cordectomy in the management of an intramedullary-extramedullary atypical meningioma: case report and literature review. J Spinal Disord Tech 18:449-454, 2005

22. Reimer R, Onofrio BM: Astrocytomas of the spinal cord in children and adolescents. J Neurosurg 63:669-675, 1985

23. Smyth MD, Peacock WJ: The surgical treatment of spasticity. Muscle Nerve 23:153-163, 2000

24. Tasker RR, DeCarvalho GT, Dolan EJ: Intractable pain of spinal cord origin: clinical features and implications for surgery. J Neurosurg 77:373-378, 1992

25. Tokoro K, Chiba Y, Yagishita S, Kunimi Y: Cordectomy for syringobulbo-myelia with sleep apnea secondary to a spinal extramedullary tumor: case report. Neurosurgery 24:118124,1989

\section{Disclosure}

The authors report no conflict of interest concerning the materials or methods used in this study or the findings specified in this paper.

\section{Author Contributions}

Conception and design: Crowley, Hamilton, Jane. Acquisition of data: Burke, Lopes, Hamilton. Drafting the article: Crowley, Burke, Lopes, Jane. Critically revising the article: all authors. Reviewed submitted version of manuscript: Crowley. Approved the final version of the manuscript on behalf of all authors: Crowley. Study supervision: Crowley.

\section{Correspondence}

R. Webster Crowley, Department of Neurological Surgery, University of Virginia Health System, Box 800212, Charlottesville, VA 22908. email: webster.crowley@virginia.edu. 